\title{
Elasticity of alcohol consumption, alcohol-related harms, and drinking initiation in low- and middle-income countries: A systematic review and meta-analysis
}

\author{
Bundit Sornpaisarn $^{1,2,3,4}$, Kevin Shield ${ }^{1,5}$, Joanna Cohen ${ }^{1,2,6,7}$, Robert Schwartz ${ }^{1,2,6}$, and Jürgen Rehm ${ }^{1,2,5,8,9}$ \\ ${ }^{1}$ Centre for Addiction and Mental Health, Toronto, Canada \\ ${ }^{2}$ Dalla Lana School of Public Health, University of Toronto, Toronto, Canada \\ ${ }^{3}$ Center for Alcohol Studies, Bangkok, Thailand \\ ${ }^{4}$ Department of Mental Health, Ministry of Public Health, Muang, Nonthaburi Province, Thailand \\ ${ }^{5}$ Institute of Medical Science (IMS), University of Toronto, Toronto, Canada \\ ${ }^{6}$ Ontario Tobacco Research Unit, Centre for Addiction and Mental Health, Toronto, Canada \\ ${ }^{7}$ Johns Hopkins Bloomberg School of Public Health, Baltimore, MD, United States \\ ${ }^{8}$ Institute for Clinical Psychology and Psychotherapy, Technische Universität Dresden, Dresden, Germany \\ ${ }^{9}$ Department of Psychiatry, University of Toronto, Toronto, Canada
}

\begin{abstract}
Aim: To systematically review research outlining the effects of price and taxation on alcohol consumption, alcohol-related harms, and drinking initiation in low- and middle-income countries (LMIC).

Design: The systematic review and meta-analyses were conducted according to internationally standardized protocols (Preferred Reporting Items for Systematic Review and Meta-Analysis; PRISMA). Data were collected up to June 2011 by searching the peer-reviewed article databases MEDLINE, EMBASE, PsycINFO, and EconLit, along with the World Health Organization's gray literature Database of Abstracts of Reviews of Effects, and by reference tracking. The meta-analyses were performed using random effects analysis, tests for publication bias, and sensitivity analyses.
\end{abstract}

Measures: Any type of association between alcohol price and/or taxation and alcohol consumption, alcohol-related harms, and alcohol drinking initiation in LMIC.

Findings: Our systematic search disclosed 12 studies that outlined an association between alcohol price or taxation and alcohol consumption in LMIC, while no articles were found that outlined a relationship between taxation and/or price and alcohol-related harms or drinking initiation in LMIC. The elasticity estimates were -0.64 (95\% CI: -0.80 to -0.48 ) for total consumption of alcohol, -0.50 (95\% CI: -0.78 to -0.21 ) for consumption of beer, and -0.79 (95\% CI: -1.09 to -0.49 ) for consumption of other alcoholic beverages. Publication bias did not significantly affect the estimated elasticities.

Conclusion: Price elasticity of demand for alcohol in LMIC is similar to that found in high-income countries. There is an imperative need for research on the association between alcohol price or taxation and alcohol-related harms and drinking initiation in LMIC.

Historically, taxation has been one of the most costeffective measures used to control alcohol consumption and the resulting related harms (Anderson, Chisholm, \& Fhur, 2009; Babor et al., 2010; Chisholm, Rehm, van Ommeren, \& Monteiro, 2004). Three systematic reviews of studies of the effects of price and/or taxation on the consumption of alcohol found that alcohol price elasticities are negative values, meaning that alcohol price negatively affects alcohol consumption and alcohol-related harms (Elder et al., 2010; Wagenaar, Salois, \& Komro, 2009; Wagenaar, Tobler, \& Komro, 2010). Elasticity measures the degree of change in one variable that is caused by one unit of change in another. For example, a price elasticity of demand of -0.5 means that a $0.5 \%$ reduction in alcohol consumption follows a $1.0 \%$ increase in alcohol price; similarly, a tax elasticity of fatal traffic accidents of -0.8 means $1.0 \%$

Correspondence: Bundit Sornpaisarn, Centre for Addiction and Mental Health, 33 Russell Street, Toronto, ON, M5S 2S1, Canada

E-mail: bundit.sornpaisarn@mail.utoronto.ca and bundit.sornpaisarn@yahoo.com

Competing interests: The authors have declared that no competing interests exist.

Financial support: Financial support for this study was provided to Bundit Sornpaisarn by the Thai Health Promotion Foundation and the Department of Mental

Health, Ministry of Public Health, Thailand. Financial support was provided to Jürgen Rehm by the U.S. National Institute for Alcohol Abuse and Alcoholism

(NIAAA) with contract number HHSN267200700041C to conduct the study titled "Alcohol- and Drug-Attributable Burden of Disease and Injury in the U.S.”

Support to CAMH for salary and infrastructure is provided by Ontario Ministry of Health and Long-Term Care.

Keywords: alcohol, elasticity, low-income countries, middle-income countries, price, taxation 
increase in alcohol tax results in a $0.8 \%$ reduction in the number of fatal traffic accidents. Wagenaar and colleagues (2009) demonstrated that the mean of price elasticity of demand is -0.46 for beer, -0.69 for wine, and -0.80 for spirits. Elder and colleagues (2010) observed that the median price elasticity is -0.50 for beer, -0.64 for wine, -0.79 for spirits, and -0.77 for ethanol. In addition, Wagenaar and colleagues (2010) observed that the price elasticity of harms was -0.347 for alcohol-related disease and injury outcomes, -0.112 for traffic crash outcomes, -0.055 for sexually transmitted diseases, -0.048 for suicide, -0.022 for violence, -0.022 for other drug use, and -0.014 for crime and other misbehavior.

Given this evidence, it is not surprising that alcohol taxation has consistently been recommended as a public policy option to control alcohol-related harms (Babor et al., 2010; World Health Organization, 2010, 2011a). At the First Global Ministerial Conference on Healthy Lifestyles and Non-Communicable Disease Control, held in April 2011, the World Health Organization (WHO) recommended alcohol taxation as one of the three "best buy" policies for controlling the harmful use of alcohol (WHO, 2011a); however, most of the literature upon which these conclusions are based is from high-income countries (HIC).

There are marked between-country differences in alcohol consumption and alcohol-attributable harms, and these differences are related to the economic wealth of nations (Rehm, Mathers et al., 2009; Room, Babor, \& Rehm, 2005; Schmidt, Mäkelä, Rehm, \& Room, 2010). The association between wealth-as measured in gross domestic product purchasing power parity (GDP-PPP) and alcohol consumption is very strong up to a GDP-PPP of $\$ 10,000$ to $\$ 15,000$, above which this association levels off (Room et al., 2005; Schmidt et al., 2010). This correlation is due mainly to a much higher proportion of abstainers in middle- and especially low-income countries (LIC) (WHO, 2011b). As a result, the lowest-income countries tend to consume the least alcohol on an adult per capita basis (Room et al., 2005). In middle-income countries (MIC) adult per capita consumption is higher than in LIC; however, consumption is still much lower than in high-income countries (HIC). Not only do the prevalence of current drinkers and the adult per capita consumption vary with economic wealth, but also the proportion of alcohol consumed by men vs. women: ceteris paribus (other things being equal), the lower the GDP-PPP, the higher the relative proportion of alcohol consumption by men (Room et al., 2005). Thus, due to differences in affordability and the characteristics of those individuals who consume alcohol, there may be different elasticities for alcohol consumption, alcoholrelated harms, and drinking initiation in low- and middleincome countries (LMIC) compared to HIC.

While less alcohol is consumed in LMIC, the relative harm associated with each liter consumed per capita is much greater (Rehm, Anderson et al., 2009) due to more harmful consumption patterns (Rehm et al., 2004), and there is a higher risk of mortality and morbidity in LMIC from causes in which alcohol plays a role (such as injuries) (Smith \& Barss, 1991). In addition, alcohol interacts with other risk factors such as poverty, crowding, and malnutrition (Schmidt, Mäkelä, Rehm, \& Room, 2010). Thus, LMIC-specific research is needed to formulate the best public policies to decrease the harms related to alcohol consumption.

Because the overwhelming majority of people who drink live in HIC (Rehm et al., 2003; WHO, 2011b), the goal of preventing people from drinking at all is rarely formulated and, thus, there is a surprising lack of research on drinking initiation; most of the focus seems to be on determining age of initiation and assessing potential consequences of different ages of initiation (Donovan, 2004; Faden, 2006; Guttmannova et al., 2011; Mares et al., 2011; Pitkanen, Lyyra, \& Pulkkinen, 2005). There is a resulting need to examine how price and taxation affects drinking initiation in LMIC.

To address the needs noted above, we performed a systematic review of studies which examined the association between alcohol price/taxation with alcohol consumption, alcohol-related harms, and drinking initiation in LMIC. Additionally, to establish a quantitative estimate of the effects of price and taxation on alcohol consumption in LMIC, we performed a meta-analysis using estimates obtained from our systematic review.

\section{Method}

The systematic review was conducted and reported according to the standards set out in Preferred Reporting Items for Systematic Review and Meta-Analysis (PRISMA) (www.prisma-statement.org/) (Moher, Liberati, Tetzlaff, Altman, \& The PRISMA Group, 2009).

\section{Search strategy and study selection}

Three public health databases-MEDLINE, EMBASE, and PsycINFO_as well as the economics database EconLit were queried up to June 2011 for articles that tested the association between alcohol taxation/price and alcohol consumption, alcohol-related harms, and drinking initiation. Where “*” is the truncation indicator to include all forms of the root word, search terms for alcohol were "alcohol," "beer*," "wine*," and "spirit*." For LMIC the search terms were "low income country," "middle income country," and "developing country." For the intervention we used the search terms " taxation," "tax*," and "price*." No limitations were put on comparison groups, outcomes, and study design for articles included in this review and, thus, no search terms were included for these variables in our systematic review. Articles were restricted to those published in English or Thai up to June 2011.

Other sources examined were WHO's Database of Abstracts of Reviews of Effects (DARE), which catalogues grey literature; all studies included in the systematic reviews of the effects of price on alcohol consumption (namely Wagenaar et al., 2009, 2010, and Elder et al., 2010); the reference lists from all of the above literature, as well as from Babor et al., 2010. 
For peer-reviewed articles, retention was based on the following inclusion scheme: (1) any article returned in the systematic search was retained for abstract screening; (2) if the abstract contained any information about alcohol taxation in LMIC, the paper was retained for full article analysis; (3) if the article examined the association between alcohol price and/or taxation with either alcohol consumption, alcohol-related harms, or drinking initiation, it was retained for quality criteria analysis.

\section{Quality criteria}

The minimum quality criteria for inclusion were as follows: (1) a longitudinal study had to have enough time points to provide a meaningful result; and (2) the results were not confounded by any other large changes in alcohol control policies that were not taken into account.

\section{Data collection}

Data extracted for each study included the sample population, intervention (price or tax), other independent variables (including socio-economic and demographic characteristics), comparison groups, outcomes (including elasticity of alcohol consumption, elasticity of related harms, and rate of drinking initiation), country of study, and own price or tax elasticity of demand and of related harms. Own price or tax elasticity is the percentage change in consumption for an alcoholic beverage that results from a $1 \%$ change in the price or tax. The potential sources of bias for studies that quantify price elasticity were assessed, and included selection bias, measurement bias, and problems with statistical analysis. To ensure consistency, data collection was performed using a data extraction form, created by the authors, consisting of the above-mentioned study variables and potential sources of bias assessment.

\section{Statistical analysis}

Our meta-analysis analyzed the reported price elasticities by means of DerSimonian and Laird's (1986) random effects. For studies that provided a probability value less than an $\alpha$ threshold, a conservative threshold of 0.001 was taken as the $p$-value. The overall point estimates and the 95\% confidence intervals (CIs) were based on weighted pooled measures. Heterogeneity between studies was assessed using the Cochran Q test and the I2 statistic. Publication bias was tested by the visual inspection of funnel plots for a skewed distribution, and by using a ranked correlation test proposed by Begg and Mazumdar (1994) and a weighted regression test proposed by Egger, Smith, Schneider, and Minder (1997). To adjust estimates for publication bias, the trim and fill method was used (Duval \& Tweedie, 2000). All data analysis was performed using Stata version 11.0 (Stata Corporation, 2009).

\section{Results}

\section{Study selection and study characteristics}

The results of the literature search are outlined in Figure 1. Search results of the databases MEDLINE, EMBASE, PsycINFO, and EconLit yielded 29 articles, which were reduced to 26 after elimination of duplicate articles. Titles and abstracts were reviewed for these 26 articles, and 4 papers were retained for full paper reviews. After the full paper reviews, no articles met the eligibility criteria of containing quantitative data relating to the price and/or taxation of alcohol and resulting effects on alcohol consumption, alcohol-related harms, and drinking initiation.

From a search of previous systematic reviews, the WHO grey literature database DARE, and reference tracking, 22 articles were identified, which were reduced to 21 after the elimination of one duplicate article. Titles and abstracts of the remaining 21 articles were reviewed and all were retained for full paper reviews. After assessing the 21 articles, seven reviews were excluded for not meeting eligibility criteria and two articles due to lack of relevant information. The remaining 12 articles contained relevant information on alcohol price and/or taxation and resulting effects on alcohol consumption in LMIC and, thus, were included in the information synthesis (Andrienko \& Nemstov, 2005; Fan, Wailes, \& Cramer, 1995; John, 2005; Musgrave \& Stern, 1988; Okello, 2001; Orsor, Mwinyimvua, \& Mpango, 2001; Ozguyen, 2004; Pan, Fang, \& Malaga, 2006; Partanen, 1991; Poapongsakorn et al., 2007; Selvanathan \& Selvanathan, 2005; Yu \& Abler, 2010).

Table 1 shows that all 12 articles contained information on the effects of alcohol price and/or taxation on alcohol consumption, while not one study contained information on the effects of alcohol price and/or taxation on alcoholrelated harms or drinking initiation. Eleven of the studies analyzed only alcohol price as the intervention of interest, while one of the studies analyzed the effects on alcohol consumption of both alcohol price and taxation. Of the 12 studies, one had a cross-sectional design, three were quasiexperimental using a series of cross-sectional surveys, and eight were quasi-experimental using time series data. One study contained data on 19 developing countries, while 11 studies focused on a single country. Overall the studies yielded 23 estimates for the effects of alcohol price and/or taxation on total alcohol consumption, nine estimates of the effects on the consumption of beer, and 11 estimates of the effects on the consumption of other alcoholic beverages (including spirits and wine). Several estimates did not include a $p$-value, $t$-value or any other statistic whereby a standard error could be calculated and, thus, were excluded from our meta-analysis. They comprised one estimate of the effects of alcohol price and/or taxation on total alcohol consumption, two estimates of the effects on the consumption of beer, and four estimates of the effects on the consumption of other alcoholic beverages. In addition, no mention of the significance of these elasticities was made in Pan et al. (2006) and Fan et al. (1995), so these 
Figure 1

Search strategy for studies that assessed the relationship between alcohol price and / or taxation with alcohol consumption, alcohol-related harms and drinking initiation

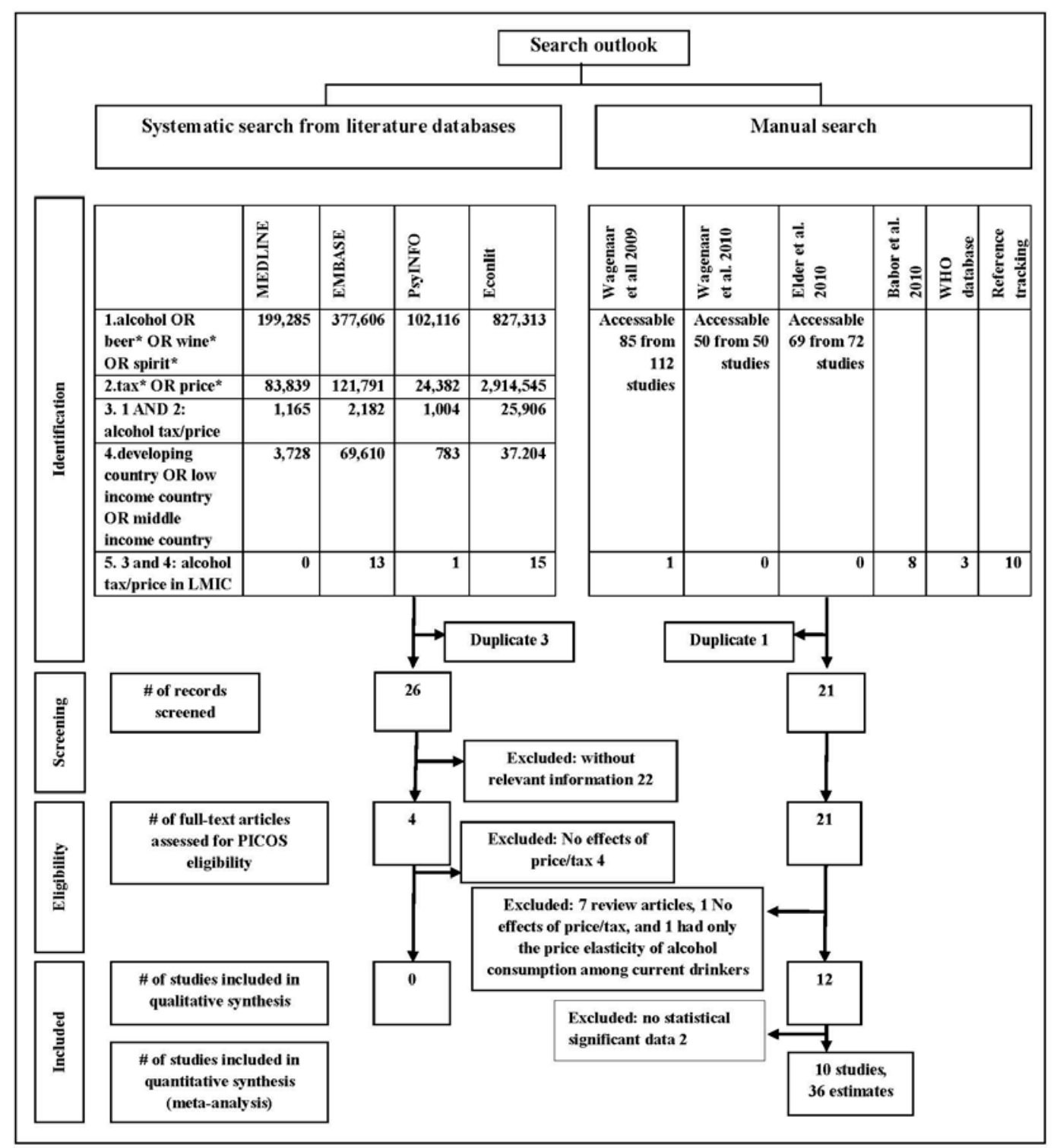

two papers were excluded from the quantitative analysis. In total, 10 studies covering 36 price elasticity estimates22 for total alcohol consumption, seven for beer and seven for other alcoholic beverages-were included in the quantitative analysis (Figure 1).

\section{Risk of bias within studies}

All 12 studies have potential selection bias. An evaluation of this bias is outlined in Table 2. Eight studies that used time series data may have selection bias due to their not taking into consideration unrecorded alcohol consumption data and thus excluding low socio-economic status populations (International Agency for Research on Cancer, 2010), and four studies that used survey data did not include important minority or high-risk groups. All 12 studies also have potential measurement bias. Six of the time series studies used alcohol sales or production data as surrogates of consumption, which may have led to an overestimation of consumption, and one time series study 


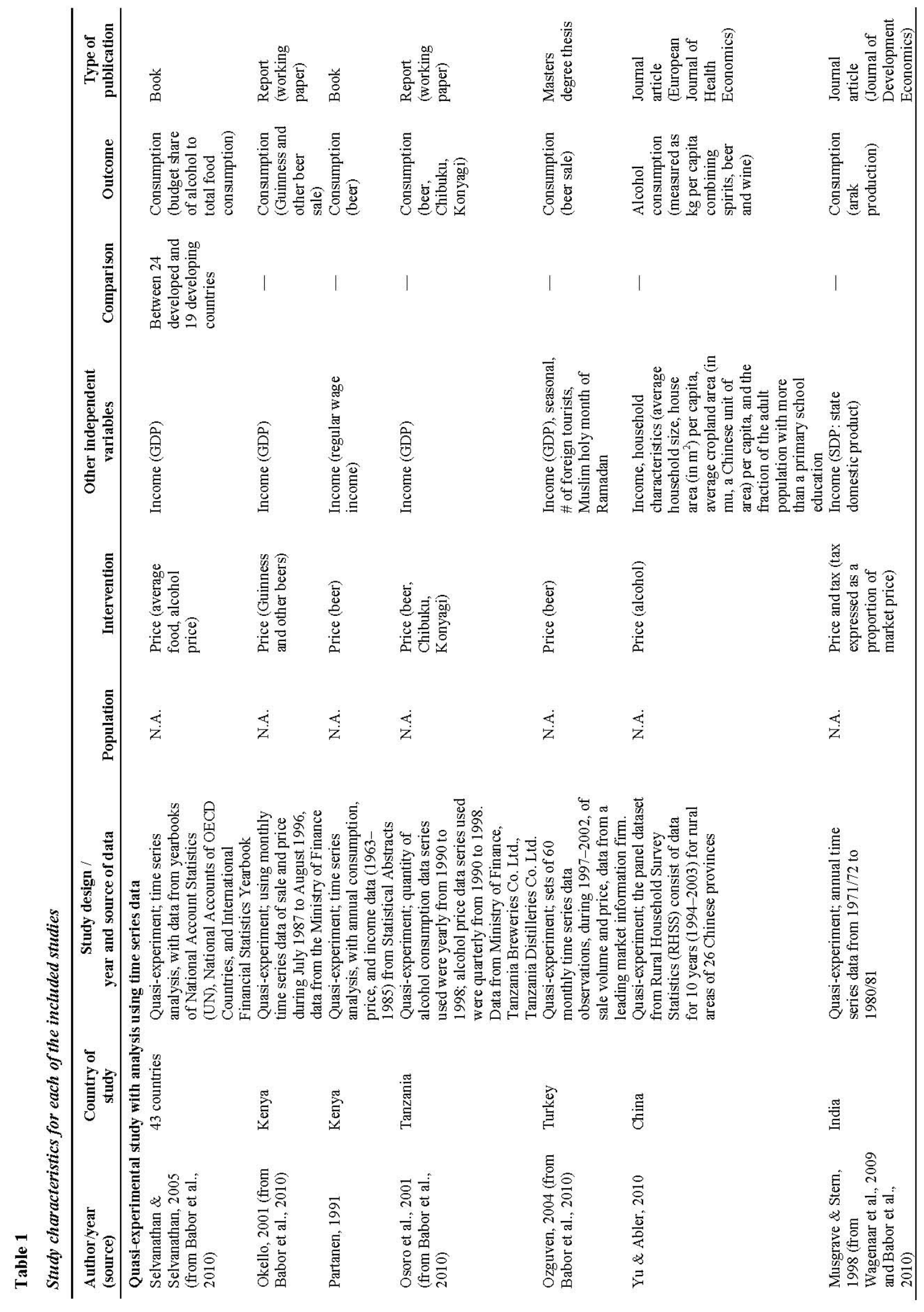




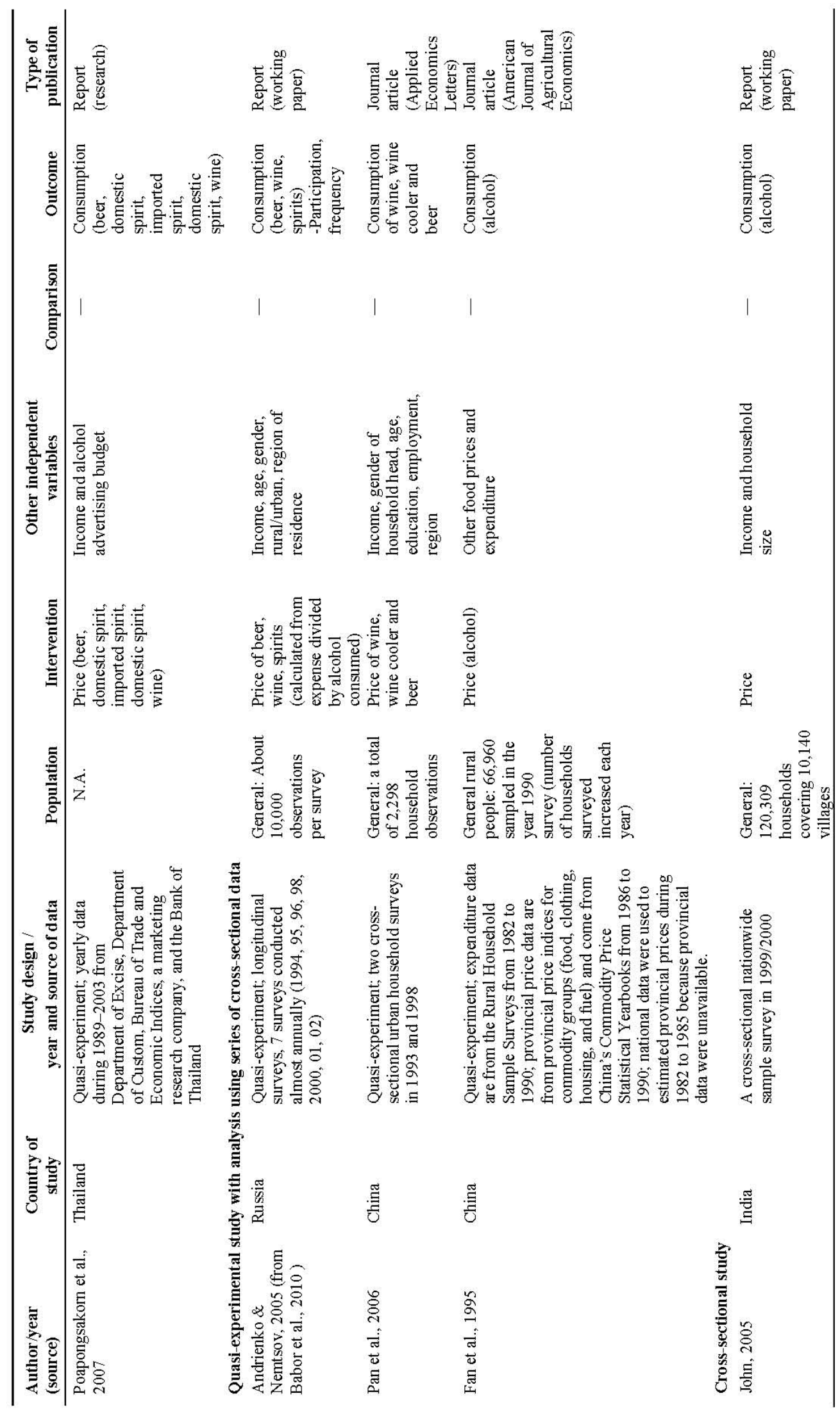


Table 2

Assessment of the risk of bias for each of study included in the systematic review

\begin{tabular}{|c|c|c|}
\hline Author/year (source) & Potential selection bias & Potential measurement bias \\
\hline \multicolumn{3}{|c|}{ Quasi-experimental study with analysis using time series data } \\
\hline $\begin{array}{l}\text { Selvanathan \& Selvanathan, } 2005 \text { (from } \\
\text { Babor et al., 2010) }\end{array}$ & $\begin{array}{l}\text { No unrecorded alcohol consumption data; } \\
\text { excludes some countries with poor databases } \\
\text { that may have different profiles of alcohol } \\
\text { drinking from the included countries }\end{array}$ & $\begin{array}{l}\text { Smaller budget share of alcohol } \\
\text { consumption may not mean lower quantity } \\
\text { of consumption if one consumes cheaper } \\
\text { alcoholic beverage }\end{array}$ \\
\hline Okello, 2001 (from Babor et al., 2010) & No unrecorded alcohol consumption data & $\begin{array}{l}\text { Alcohol sales data may overestimate } \\
\text { consumption data }\end{array}$ \\
\hline Partanen, 1991 & No unrecorded alcohol consumption data & $\begin{array}{l}\text { Alcohol sales data may overestimate } \\
\text { consumption data }\end{array}$ \\
\hline Osoro et al., 2001 (from Babor et al., 2010 ) & No unrecorded alcohol consumption data & $\begin{array}{l}\text { Alcohol sales data may overestimate } \\
\text { consumption data }\end{array}$ \\
\hline Ozguven, 2004 (from Babor et al., 2010) & No unrecorded alcohol consumption data & $\begin{array}{l}\text { Alcohol sales data may overestimate } \\
\text { consumption data }\end{array}$ \\
\hline Yu \& Abler, 2010 & No unrecorded alcohol consumption data & $\begin{array}{l}\text { Alcohol sales data may overestimate } \\
\text { consumption data }\end{array}$ \\
\hline $\begin{array}{l}\text { Musgrave \& Stern, } 1988 \text { (from Wagenaar et } \\
\text { al., } 2009 \text { and Babor et al., 2010) }\end{array}$ & No unrecorded alcohol consumption data & $\begin{array}{l}\text { Alcohol sales data may overestimate } \\
\text { consumption data }\end{array}$ \\
\hline Poapongsakorn et al., 2007 & No unrecorded alcohol consumption data & $\begin{array}{l}\text { Alcohol sales data may overestimate } \\
\text { consumption data }\end{array}$ \\
\hline \multicolumn{3}{|c|}{ Quasi-experimental study with analysis using series of cross-sectional data } \\
\hline $\begin{array}{l}\text { Andrienko \& Nemtsov, } 2005 \text { (from Babor et } \\
\text { al., 2010) }\end{array}$ & $\begin{array}{l}\text { No sample of minority groups such as } \\
\text { homeless people or immigrants who have } \\
\text { higher possibility of heavy drinking }\end{array}$ & Subject to recall bias \\
\hline Pan et al., 2006 & $\begin{array}{l}\text { This study is an urban household survey and } \\
\text { does not include rural population }\end{array}$ & Subject to recall bias \\
\hline Fan et al., 1995 & $\begin{array}{l}\text { This study is a rural household survey that } \\
\text { does not include urban population }\end{array}$ & Subject to recall bias \\
\hline \multicolumn{3}{|l|}{ Cross-sectional survey } \\
\hline John, 2005 & $\begin{array}{l}\text { No sample of minority groups who have } \\
\text { higher possibility of heavy drinking }\end{array}$ & Subject to recall bias \\
\hline
\end{tabular}

Note. Problem(s) with statistical analysis for all papers were restricted to mainly economic and partly demographic variables.

Other bias/problem - no comparison group (no counterfactual effect) for all papers except for John (2005) where there was a temporal bias and no comparison group (no counterfactual effect). Summaries of all papers were included in the result synthesis, with no unacceptable severe error.

used budget share of alcohol as a proportion of total food costs as a determination of consumption, which may have led to bias. A smaller budget share of alcohol consumption may not translate into a lower quantity of consumption if people instead consume less expensive alcoholic beverages. All 12 studies are limited by the narrow scope of variables analyzed-mainly economic and partly demographic variables. Although each study is susceptible to bias, these biases are hard to avoid in non-experimental research, and thus each study met the eligibility criteria and minimal standard. Hence, 12 and 10 studies were included in the qualitative and quantitative syntheses respectively, as explained above in the study selection section.

\section{Meta-analysis}

Random effects analysis indicated a significant negative elasticity for alcohol consumption. Tests demonstrated that heterogeneity in the estimates was present for consumption in all studies $[\mathrm{Q}(35)=289.57, p=0.000$; $\mathrm{I} 2=87.9 \%]$, for total alcohol consumption $[\mathrm{Q}(21)=129.08, p=0.000$; $\mathrm{I} 2=$ $83.7 \%]$ and for consumption of beer $[\mathrm{Q}(6)=19.31, p=$ $0.004 ; \mathrm{I} 2=68.9 \%]$, but not for consumption of other alcoholic beverages $[\mathrm{Q}(6)=5.94, p=0.430 ; \mathrm{I} 2=0.0 \%]$.

The forest plots for total consumption of alcohol, consumption of beer and consumption of other alcoholic beverages are outlined in Figures 2 to 4 respectively. The forest plot for all studies can be found in Appendix Figure 1. Our analysis showed an elasticity in LMIC of -0.66 (95\% CI: -0.82 to -0.50 ) for consumption of all alcoholic beverages, -0.64 (95\% CI: -0.80 to -0.48$)$ for total consumption of alcohol, -0.50 (95\% CI: -0.78 to -0.21 ) for consumption of beer, and -0.79 (95\% CI: -1.09 to -0.49) for consumption of other alcoholic beverages. Only 
Figure 2

Forest plot of the 22 estimates used in the meta-analysis and the weighted point estimates for the price elasticity of total alcohol consumption

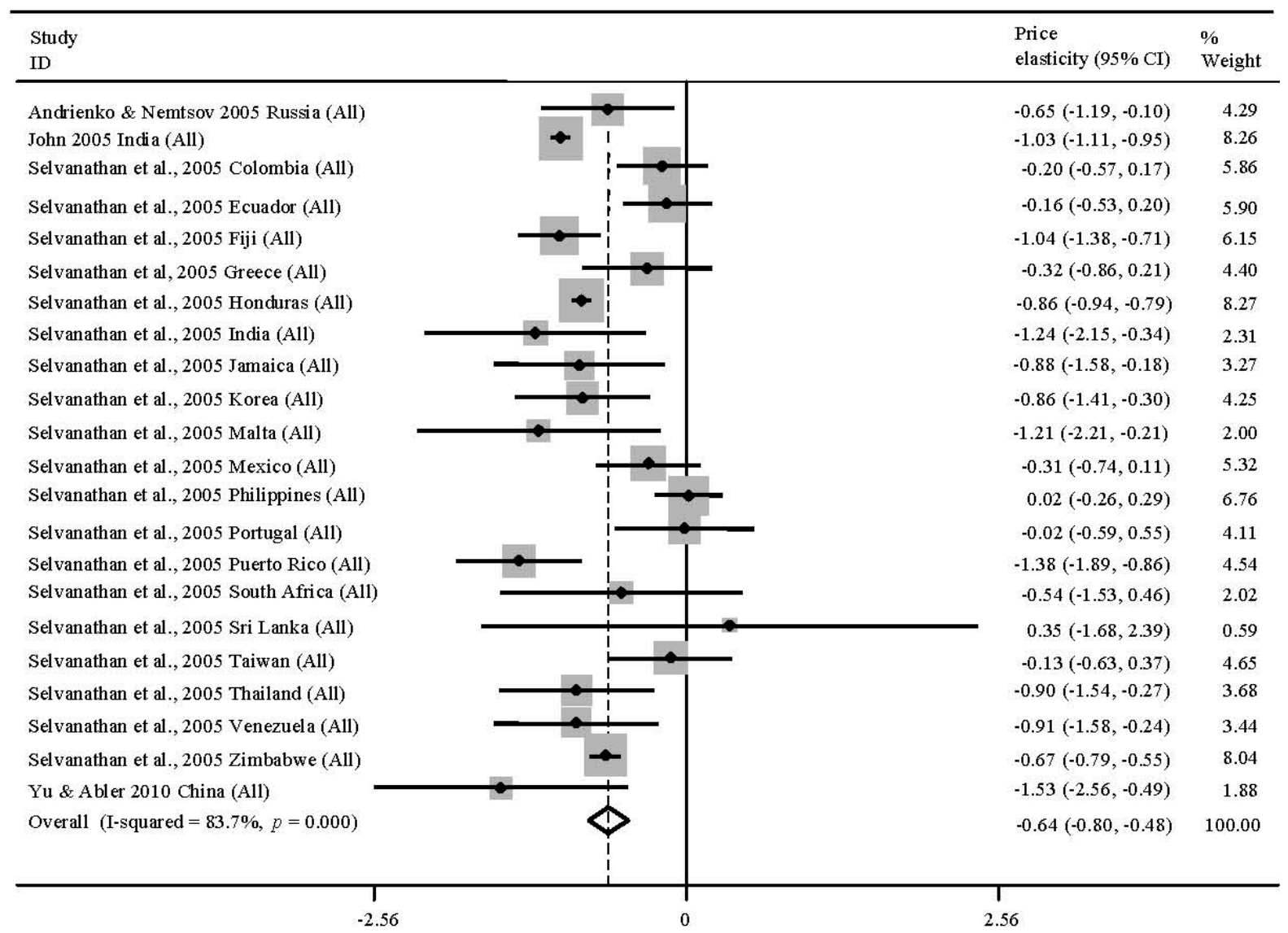

Note. Weights are from random effects analysis. The size of the box around the estimate is representative of the weight of the estimate in calculating the aggregate point estimate.

two estimates, for total consumption of alcohol in Sri Lanka and the Philippines, had a positive elasticity estimate of alcohol consumption, and 11 had elasticity estimates that were non-significant.

Publication bias appeared to be present for the elasticities of all studies (Egger [ $p=0.761]$ and Begg $[p=0.002]$ ), total consumption of alcohol (Egger [ $p=0.073]$, Begg [ $p=$ $0.159]$ ), consumption of beer (Egger $[p=0.001]$, Begg [ $p=$ $0.035]$ ), and consumption of other alcoholic beverages (Egger [ $p=0.003]$, Begg [ $p=0.072]$ ); however, the extent of publication bias was not enough to initiate a fit and trim adjustment. The funnel plots for the elasticities of the consumption in all studies, total alcohol consumption, consumption of beer, and the consumption of other alcoholic beverages can be found in Appendix Figures 2 to 5 .

\section{Discussion}

Our systematic review found 12 original studies that investigated alcohol price/taxation elasticity in LMIC, but no articles that investigated the association between alcohol price/taxation and alcohol-related harms or drinking initiation.

The review found an inverse relationship between alcohol price and/or taxation and alcohol consumption, similar to what has been observed in HIC (Babor et al., 2010; Elder et al., 2010; Wagenaar et al., 2010; Wagenaar et al., 2009), with similar estimates for price elasticity. Specifically, price elasticities in HIC are -0.46 for beer, -0.69 for wine, -0.80 for spirits and -0.77 for median price elasticity of ethanol (Elder et al., 2010; Wagenaar et al., 2009). For LMIC, we observed price elasticities of -0.50 for beer, -0.79 for other alcoholic beverages, -0.64 for total alcohol consumption and -0.66 for all studies. This finding is counter-intuitive, given that alcoholic beverages are less affordable in LMIC than in HIC (Babor et al., 2010). For example, in Thailand, a middle-income country, a worker has to work six times longer (48 minutes) than does a Canadian worker (8 minutes) to accumulate sufficient funds to purchase a can of beer (calculated based on the lowest price of a can of beer and the minimum wage for both countries as of September 2011). 
Figure 3

Forest plot of the 7 estimates used in the meta-analysis and the weighted point estimates for the price elasticity for the consumption of beer

\begin{tabular}{|c|c|c|}
\hline $\begin{array}{l}\text { Study } \\
\text { ID }\end{array}$ & $\begin{array}{l}\text { Price } \\
\text { elasticity }(95 \% \mathrm{CI})\end{array}$ & $\begin{array}{l}\% \\
\text { Weight }\end{array}$ \\
\hline Andrienko \& Nemtsov 2005 Russia (Beer) & $-3.02(-5.57,-0.47)$ & 1.17 \\
\hline Osoro \& Mwinyimvua 2001 Tanzania (Beer) & $-0.22(-0.31,-0.12)$ & 29.31 \\
\hline Özgüven 2004 Turkey (Beer) & $-0.37(-0.71,-0.03)$ & 20.86 \\
\hline Partanen 1991 Kenya (Beer) & $-0.33(-0.59,-0.07)$ & 24.06 \\
\hline Poapongsakorn et al., 2007 Thailand (Beer) & $-2.68(-4.55,-0.81)$ & 2.10 \\
\hline Okello 2001 Kenya (Beer [guinness]) & $-1.13(-2.30,0.04)$ & 4.83 \\
\hline Okello 2001 Kenya (Beer [other]) & $-0.74(-1.17,-0.31)$ & 17.67 \\
\hline Overall (I-squared $=68.9 \%, p=0.004)$ & $-0.50(-0.78,-0.22)$ & 100.00 \\
\hline
\end{tabular}

Note. Weights are from random effects analysis

\section{Figure 4}

Forest plot of the 7 estimates used in the meta-analysis and the weighted point estimates for the price elasticity for the consumption of other alcoholic beverages

\begin{tabular}{|c|c|c|}
\hline $\begin{array}{l}\text { Study } \\
\text { ID }\end{array}$ & $\begin{array}{l}\text { Price } \\
\text { elasticity }(95 \% \mathrm{CI})\end{array}$ & $\begin{array}{l}\% \\
\text { Weight }\end{array}$ \\
\hline Musgrave 1998 India (Arrack) & $-1.14(-1.98,-0.30)$ & 12.84 \\
\hline Osoro \& Mwinvimvua 2001 Tanzania (Chibuku) & $-0.53(-1.02,-0.04)$ & 37.76 \\
\hline Andrienko \& Nemtsov 2005 Russia (Vodka) & $-1.77(-3.27,-0.28)$ & 4.00 \\
\hline Andrienko \& Nemtsov 2005 Russia (Wine) & $-1.04(-1.93,-0.16)$ & 11.54 \\
\hline Poapongsakorn et al., 2007 Thailand (Brown Spirits) & $-1.56(-3.12,-0.00)$ & 3.70 \\
\hline Poapongsakorn et al., 2007 Thailand (Imported Spirits) & $-0.61(-1.16,-0.06)$ & 29.63 \\
\hline $\begin{array}{l}\text { Poapongsakorn et al., } 2007 \text { Thailand } \\
\text { (White Spirits) }\end{array}$ & $-2.73(-6.88,1.42)$ & 0.52 \\
\hline Overall (I-squared $=0.0 \%, p=0.430)$ & $-0.79(-1.09,-0.49)$ & 100.00 \\
\hline
\end{tabular}

Note. Weights are from random effects analysis 
The observation that there are similar price elasticities in HIC and LMIC may be confounded by unrecorded consumption, because the substitution of unrecorded alcohol consumption may occur in both LMIC and HIC when prices of recorded alcoholic beverages increase (Rehm, Chisholm, Room, \& Lopez, 2006). More research is needed to determine the relationship between the unrecorded and the recorded alcohol markets to characterize how taxation and/or price is associated with total alcohol consumption. Specifically there is a need to quantify the association between the taxation of alcohol, and informal production and smuggling. This may be especially important for LMIC, which often have a limited capacity to deter illegal production (Centre for Social and Health Outcomes Research and Evaluation, 2006).

No study has examined the effect of alcohol price and/or taxation on drinking initiation in LMIC. Studies examining this issue are needed, because the effects of alcohol price and taxation may differ between HIC and LMIC due to differing prevalences of abstainers. Currently, specific taxation, based on alcohol content (\% of alcohol by volume), is suggested in LMIC (Anderson et al., 2009); however, this type of taxation favours low alcohol content beverages, which works well in HIC, but may encourage drinking initiation among youth in LMIC (Sornpaisarn, Shield, \& Rehm, 2012). Thus, original research studies should be conducted to examine the effects of alcohol price and/or taxation on drinking initiation in LMIC.

There are a number of limitations of this systematic review. First, only a small number of studies examine the effects of alcohol price and/or taxation in LMIC, so if there are regional differences in LMIC we are unable to detect them based on the available data. Second, there may be studies in LMIC published in languages other than English or Thai that were consequently excluded from our review. Finally, the question of unrecorded consumption has not been addressed sufficiently and thus measurement error cannot be excluded (Lachenmeier, Taylor, \& Rehm, 2011).

\section{References}

Anderson, P., Chisholm, D., \& Fuhr D. (2009). Effectiveness and cost-effectiveness of policies and programmes to reduce the harm caused by alcohol. Lancet, 373, 2234-2246.

Andrienko, Y., \& Nemstov, A. (2005). Estimation of individual demand for alcohol. Moscow, Russia: Economics, Education and Research Consortium.

Babor, T., Caetano, R., Casswell, S., Edwards, G., Giesbrecht, N., Graham, K., ... Rossow, I. (2010). Alcohol: No ordinary commodity. Research and public policy (2nd ed.). Oxford, England: Oxford University Press.

Begg, C. B., \& Mazumdar, M. (1994). Operating characteristics of a rank correlation test for publication bias. Biometrics, 50, 1088-1101.

Centre for Social and Health Outcomes Research and Evaluation (2005). Alcohol taxation in the Western Pacific Region. Albany, New Zealand: Author.
Chisholm, D., Rehm, J., van Ommeren, M., \& Monteiro, M. (2004). Reducing the global burden of hazardous alcohol use: A comparative cost-effectiveness analysis. Journal of Studies on Alcohol, 65, 782-793.

DerSimonian, R., \& Laird, N. (1986). Meta-analysis in clinical trials. Controlled Clinical Trials, 7, 177-188.

Donovan, J. E. (2004). Adolescent alcohol initiation: Review of psychosocial risk factors. Journal of Adolescent Health, 35, 529e7-529e18.

Duval, S. J., \& Tweedie, R. L. (2000). Trim and fill: A simple funnel plot-based method of testing and adjusting for publication bias in meta-analysis. Biometrics, 56, 276-284.

Elder, R. W., Lawrence, B., Ferguson, A., Naimi, T. S., Brewer, R. D., Chattopadhyay, S. K., .. . Fielding, J. E. (2010). The effectiveness of tax policy interventions for reducing excessive alcohol consumption and related harms. American Journal of Preventive Medicine, 38, 217-229.

Egger, M., Smith, G. D., Schneider, M., \& Minder, C. (1997). Bias in meta-analysis detected by a simple, graphical test. British Medical Journal, 15, 629-634.

Faden, V. B. (2006). Trends in initiation of alcohol use in the United States 1975 to 2003. Alcoholism: Clinical and Experimental Research, 30, 1011-1022.

Fan, S., Wailes, E. J., \& Cramer, G. L. (1995). Household demand in rural China: A two-stage LES-AIDS model. American Journal of Agricultural Economics, 77, 54-62.

Guttmannova, K., Bailey, J. A., Hill, K. G., Lee, J. O., Hawkins, J. D., Woods, M. L., \& Catalano, R. F. (2011). Sensitive periods for adolescent alcohol use initiation: Predicting the lifetime occurrence and chronicity of alcohol problems in adulthood. Journal of Studies on Alcohol and Drugs, 72, 221-231.

International Agency for Research on Cancer. (2010). IARC Monographs on the evaluation of carcinogenic risks to humans: Alcohol consumption and ethyl cabamate. Lyon, France: Author.

John, R. M. (2005). Price elasticity estimates for tobacco and other addictive goods in India. Mumbai, India: Economics, Education and Research Consortium.

Lachenmeier, D. W., Taylor, B. J., \& Rehm, J. (2011). Alcohol under the radar: Do we have policy options regarding unrecorded alcohol? International Journal of Drug Policy, 22, 153-160.

Mares, S. H. W., van der Vorst, H., Lichtwarck-Aschoff, A., Schulten, I., Verdurmen, J. E. E., Otten, R., ... Engles, R. (2011). Effectiveness of the home-based alcohol prevention program "In control: No alcohol!": Study protocol of a randomized controlled trial. BMC Public Health, 11, 622.

Moher, D., Liberati, A., Tetzlaff, J., Altman, D. G., \& The PRISMA Group. (2009). Preferred reporting items for systematic reviews and meta-analyses: The PRISMA Statement. PLoS Medicine, 6, e1000097. doi: 10.1371/journal.pmed.1000097

Musgrave, S., \& Stern, N. (1988). Alcohol: Demand and taxation under monopoly and oligopoly in South India in the 1970s. The Amsterdam Journal, 28, 1-41.

Okello, A. K. (2001). An analysis of excise taxation in Kenya. Nairobi, Kenya: Ministry of Finance. 
Osoro, N. E., Mwinyimvua, H. H., \& Mpango, P. I. N. (2001). An analysis of excise taxation in Tanzania. Journal of African Economies, 72, 1-25.

Ozguven, C. (2004). Analysis of demand and pricing policies in Turkey beer market (Doctoral Dissertation). Istanbul, Turkey: The Graduate School of Natural and Applied Sciences of Middle East Technical University.

Pan, S., Fang, C., \& Malaga, J. (2006). Alcoholic beverage consumption in China: A censored demand system approach. Applied Economics, 13, 975-979.

Partanen, J. (1991). Sociability and intoxication: Alcohol and drinking in Kenya, Africa, and the modern world. Helsinki, Finland: Finnish Foundation for Alcohol Studies.

Pitkanen, T., Lyyra, A. L., \& Pulkkinen, L. (2005). Age of onset of drinking and the use of alcohol in adulthood: A follow-up study from age 8-42 for females and males. Addiction, 100, 652-661.

Poapongsakorn, N., Leehanon, S., Laowakun, D., Tasarika, A., Methasurarak, S., ... Jittareekunm T. (2007). Assessment of the impact of liquor taxes on prices and consumption of liquor. Bangkok, Thailand: Center for Alcohol Studies.

Rehm, J., Anderson, P., Kanteres, F., Parry, C. D., Samokhvalov, A. V., \& Patra, J. (2009). Alcohol, social development and infectious disease. Eurocare, December 18. Retrieved from: http://www.euro care.org/library/eurocare_updates/alcohol_social_deve lopment_and_infectious_disease_new_report

Rehm, J., Chisholm, D., Room, R., \& Lopez, A. D. (2006) Disease control priorities in developing countries. In D. T. Jamison (Ed.), Disease control priorities project (pp. 887-906). Washington, DC, United States: World Bank.

Rehm, J., Mathers, C., Popova, S., Thavorncharoensap, M., Teerawattananon, Y., \& Patra, J. (2009). Global burden of disease and injury and economic cost attributable to alcohol use and alcohol use disorders. Lancet, 373, 2223-2233.

Rehm, J., Room, R., Monteiro, M., Gmel, G., Graham, K., Rehn, N., ... Jernigan, D. (2004). Alcohol use. In M. Ezzati, A. D. Lopez, A. Rodgers, \& C. J. L. Murray (Eds.), Comparative quantification of health risks: Global and regional burden of disease attributable to selected major risk factors (pp. 961-1109). Geneva, Switzerland: World Health Organization.
Rehm, J., Rehn, N., Room, R., Monteiro, M., Gmel, G., Jernigan, D., \& Frick, U. (2003). The global distribution of average volume of alcohol consumption and patterns of drinking. European Addiction Research, 9, 147-156.

Room, R., Babor, T., \& Rehm, J. (2005). Alcohol and public health: A review. Lancet, 365, 519-530.

Schmidt, L. A., Mäkelä, P., Rehm, J., \& Room, R. (2010) Alcohol: Equity and social determinants. In E. Blas \& A. Sivasankara Kurup (Eds.), Equity, social determinants and public health programmes (pp. 1130). Geneva, Switzerland: World Health Organization.

Selvanathan, S., \& Selvanathan, E. A. (2005). The demand for alcohol, tobacco and marijuana: International evidence. Burlington, VT, United States: Ashgate Publishing.

Sornpaisarn, B., Shield, K., Rehm, J. (2012). Alcohol taxation policy in Thailand: Implications for other low- to middle-income countries. Addiction, 107, 1372-1384.

Smith, G. S., \& Barss, P. (1991). Unintentional injuries in developing countries: The epidemiology of a neglected problem. Epidemiologic Reviews, 13, 228266.

Stata Corporation. (2009). Statistical Software: Release 11.0. College Station, TX, United States: Author.

Wagenaar, A. C., Salois, M. J., \& Komro, K. A. (2009). Effects of beverage alcohol price and tax levels on drinking: A meta-analysis of 1003 estimates from 112 studies. Addiction, 104, 179-190.

Wagenaar, A. C., Tobler, A. L., \& Komro, K. A. (2010). Effects of alcohol tax price policies on morbidity and mortality: A systematic review. American Journal of Public Health, 100, 2270-2278.

World Health Organization. (2011a). Global status report on noncommunicable diseases 2010. Description of the global burden of NCDs, their risk factors and determinants. Geneva, Switzerland: Author.

World Health Organization (2011b). Global status report on alcohol and health. Geneva, Switzerland: Author.

World Health Organization. (2010). Global strategy to reduce the harmful use of alcohol. Geneva, Switzerland: Author.

Yu, X., \& Abler, D. (2010). Interactions between cigarette and alcohol consumption in rural China. European Journal of Health Economics, 11, 151-160. 


\section{Appendices}

\section{Appendix Figure 1}

Forest plot of all estimates used in the meta-analysis and the weighted point estimates for the price elasticity of total alcohol consumption

\begin{tabular}{|c|c|c|}
\hline $\begin{array}{l}\text { Study } \\
\text { ID }\end{array}$ & $\begin{array}{l}\text { Price } \\
\text { elasticity }(95 \% \mathrm{CI})\end{array}$ & $\begin{array}{l}\% \\
\text { Weight }\end{array}$ \\
\hline Andrienko \& Nemtsov 2005 Russia (All) & $-0.65(-1.19,-0.10)$ & 3.10 \\
\hline John 2005 India & $-1.03(-1.11,-0.95)$ & 4.91 \\
\hline Selvanathan et al., 2005 Colombia (All) & $-0.20(-0.57,0.17)$ & 3.90 \\
\hline Selvanathan et al.. 2005 Ecuador (All) & $-0.16(-0.53,0.20)$ & 3.92 \\
\hline Selvanathan et al., 2005 Fiji (All) & $-1.04(-1.38,-0.71)$ & 4.04 \\
\hline Selvanathan et al., 2005 Greece (All) & $-0.32(-0.86,0.21)$ & 3.16 \\
\hline Selvanathan et al., 2005 Honduras (All) & $-0.86(-0.94,-0.79)$ & 4.91 \\
\hline Selvanathan et al., 2005 India (All) & $-1.24(-2.15,-0.34)$ & 1.88 \\
\hline Selvanathan et al., 2005 Jamaica (All) & $-0.88(-1.58,-0.18)$ & 2.50 \\
\hline Selvanathan et al., 2005 Korea (All) & $-0.86(-1.41,-0.30)$ & 3.08 \\
\hline Selvanathan et al.. 2005 Malta (All) & $-1.21(-2.21,-0.21)$ & 1.65 \\
\hline Selvanathan et al., 2005 Mexico (All) & $-0.31(-0.74,0.11)$ & 3.64 \\
\hline Selvanathan et al., 2005 Philippines (All) & $0.02(-0.26,0.29)$ & 4.31 \\
\hline Selvanathan et al., 2005 Portugal (All) & $-0.02(-0.59,0.55)$ & 3.00 \\
\hline Selvanathan et al., 2005 Puerto Rico (All) & $-1.38(-1.89,-0.86)$ & 3.24 \\
\hline Selvanathan et al., 2005 South Africa (All) & $-0.54(-1.53,0.46)$ & 1.66 \\
\hline Selvanathan et al., 2005 Sri Lanka (All) & $0.35(-1.68,2.39)$ & 0.53 \\
\hline Selvanathan et al., 2005 Taiwan (All) & $-0.13(-0.63,0.37)$ & 3.30 \\
\hline Selvanathan et al., 2005 Thailand (All) & $-0.90(-1.54,-0.27)$ & 2.75 \\
\hline Selvanathan et al., 2005 Venezuela (All) & $-0.91(-1.58,-0.24)$ & 2.61 \\
\hline Selvanathan et al., 2005 Zimbabwe (All) & $-0.67(-0.79,-0.55)$ & 4.83 \\
\hline Yu \& Abler 2010 China (All) & $-1.53(-2.56,-0.49)$ & 1.57 \\
\hline Musgrave 1998 India (Arrack) & $-1.14(-1.98,-0.30)$ & 2.06 \\
\hline Andrienko \& Nemtsov 2005 Russia (Beer) & $-3.02(-5.57,-0.47)$ & 0.35 \\
\hline Osoro \& Mwinyimvua 2001 Tanzania (Beer) & $-0.22(-0.31,-0.12)$ & 4.88 \\
\hline Özgüven 2004 Turkey (Beer) & $-0.37(-0.71,-0.03)$ & 4.02 \\
\hline Partanen 1991 Kenya (Beer) & $-0.33(-0.59,-0.07)$ & 4.37 \\
\hline Poapongsakorn et al., 2007 Thailand (Beer) & $-2.68(-4.55,-0.81)$ & 0.62 \\
\hline Okello 2001 Kenya (Beer [guinness]) & $-1.13(-2.30,0.04)$ & 1.32 \\
\hline Okello 2001 Kenya (Beer [other]) & $-0.74(-1.17,-0.31)$ & 3.62 \\
\hline Poapongsakorn et al., 2007 Thailand (Brown spirits) & $-1.56(-3.12,-0.00)$ & 0.84 \\
\hline Osoro \& Mwinyimvua 2001 Tanzania (Chibuku) & $-0.53(-1.02,-0.04)$ & 3.36 \\
\hline Poapongsakorn et al., 2007 Thailand (Imported spirits) & $-0.61(-1.16,-0.06)$ & 3.08 \\
\hline Andrienko \& Nemtsov 2005 Russia (Vodka) & $-1.77(-3.27,-0.28)$ & 0.90 \\
\hline $\begin{array}{l}\text { Poapongsakorn et al., } 2007 \text { Thailand } \\
\text { (White spirits) }\end{array}$ & $-2.73(-6.88,1.42)$ & 0.14 \\
\hline Andrienko \& Nemtsov 2005 Russia (Wine) & $-1.04(-1.93,-0.16)$ & 1.93 \\
\hline Overall (I-squared $=87.9 \%, p=0.000)$ & $-0.66(-0.82,-0.51)$ & 100.00 \\
\hline-6.88 & $\frac{1}{6.88}$ & \\
\hline
\end{tabular}

Note. Weights are from random effects analysis 


\section{Appendix Figure 2}

Funnel plot of all estimates used in the meta-analysis with pseudo 95\% confidence intervals.

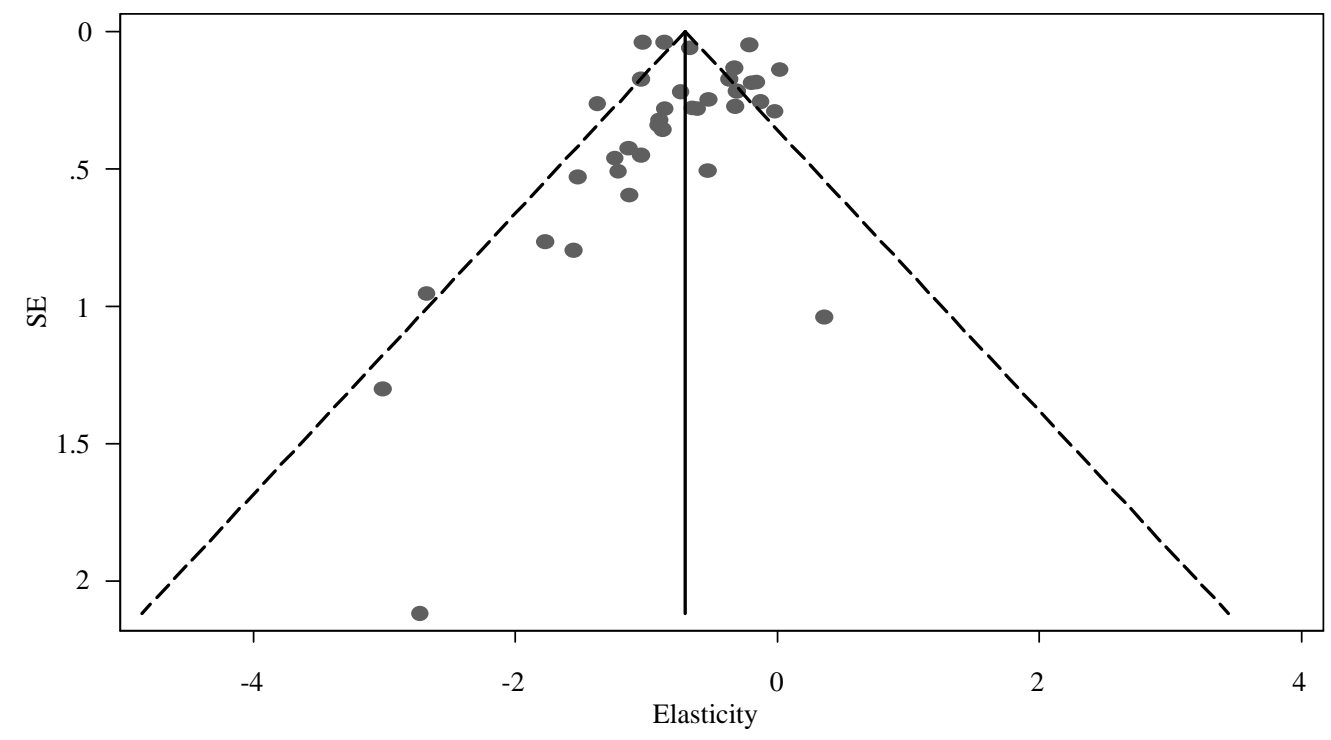

\section{Appendix Figure 3}

Funnel plot of the 22 estimates used in the meta-analysis for the price elasticity of total alcohol consumption with pseudo $95 \%$ confidence intervals

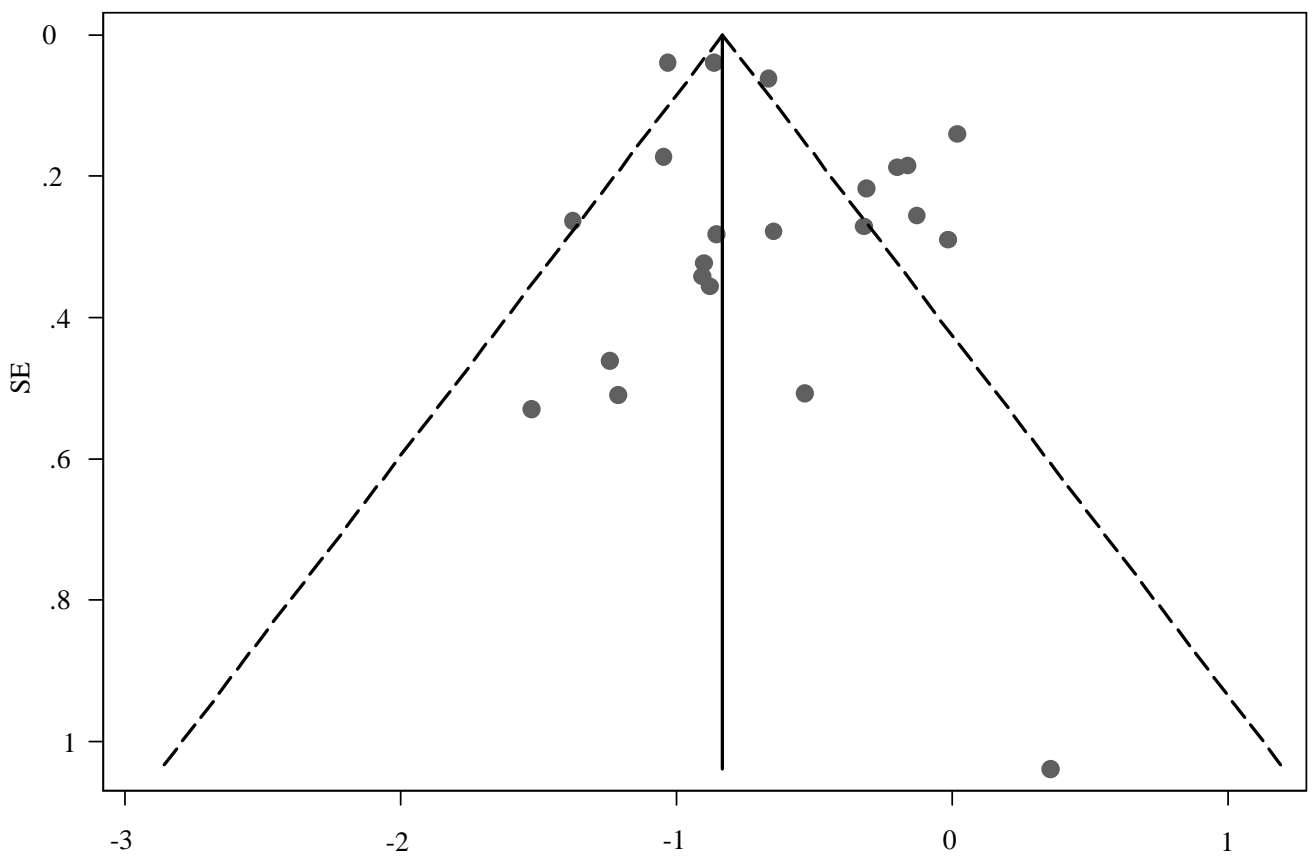




\section{Appendix Figure 4}

Funnel plot of the 7 estimates used in the meta-analysis for the price elasticity for the consumption of beer with pseudo $95 \%$ confidence intervals

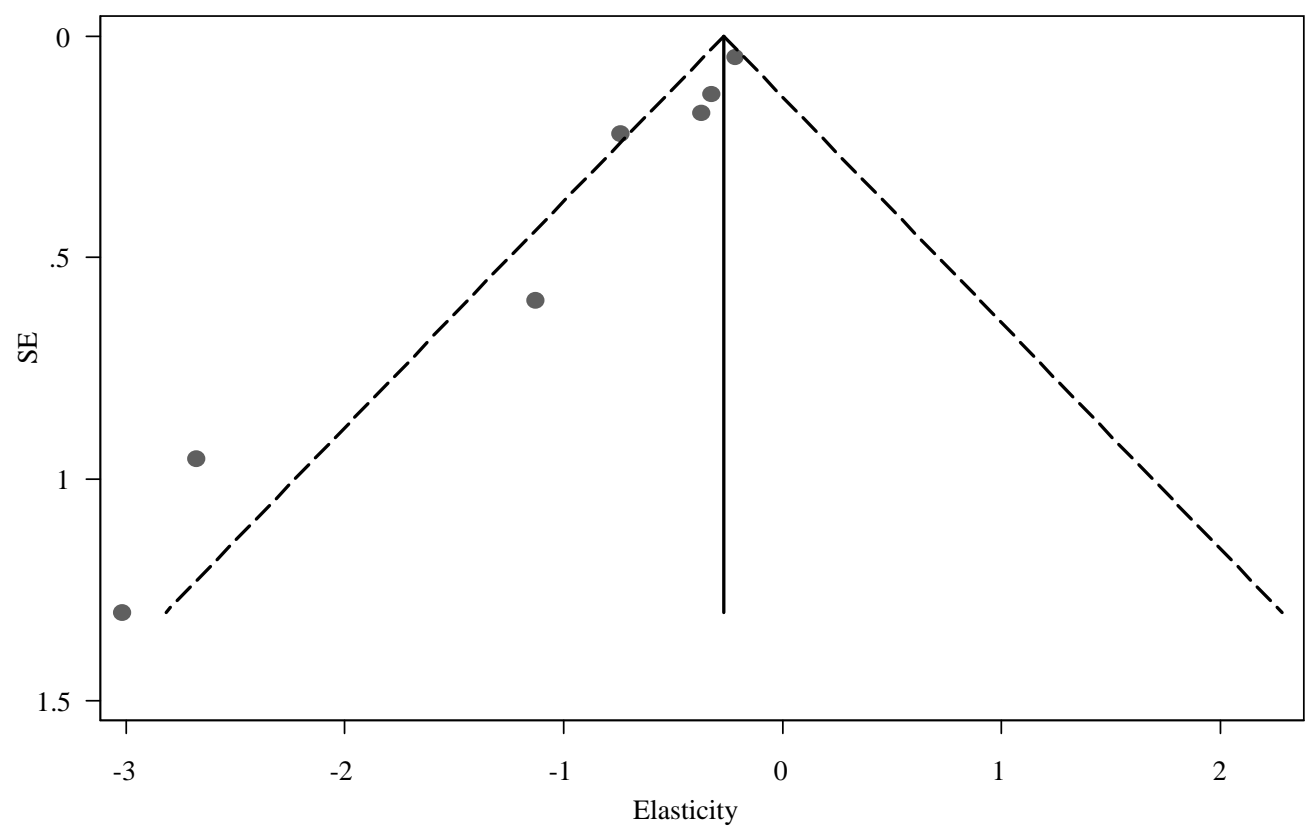

Appendix Figure 5

Funnel plot of the 7 estimates used in the meta-analysis for the price elasticity for the consumption of other alcoholic beverages with pseudo $95 \%$ confidence intervals.

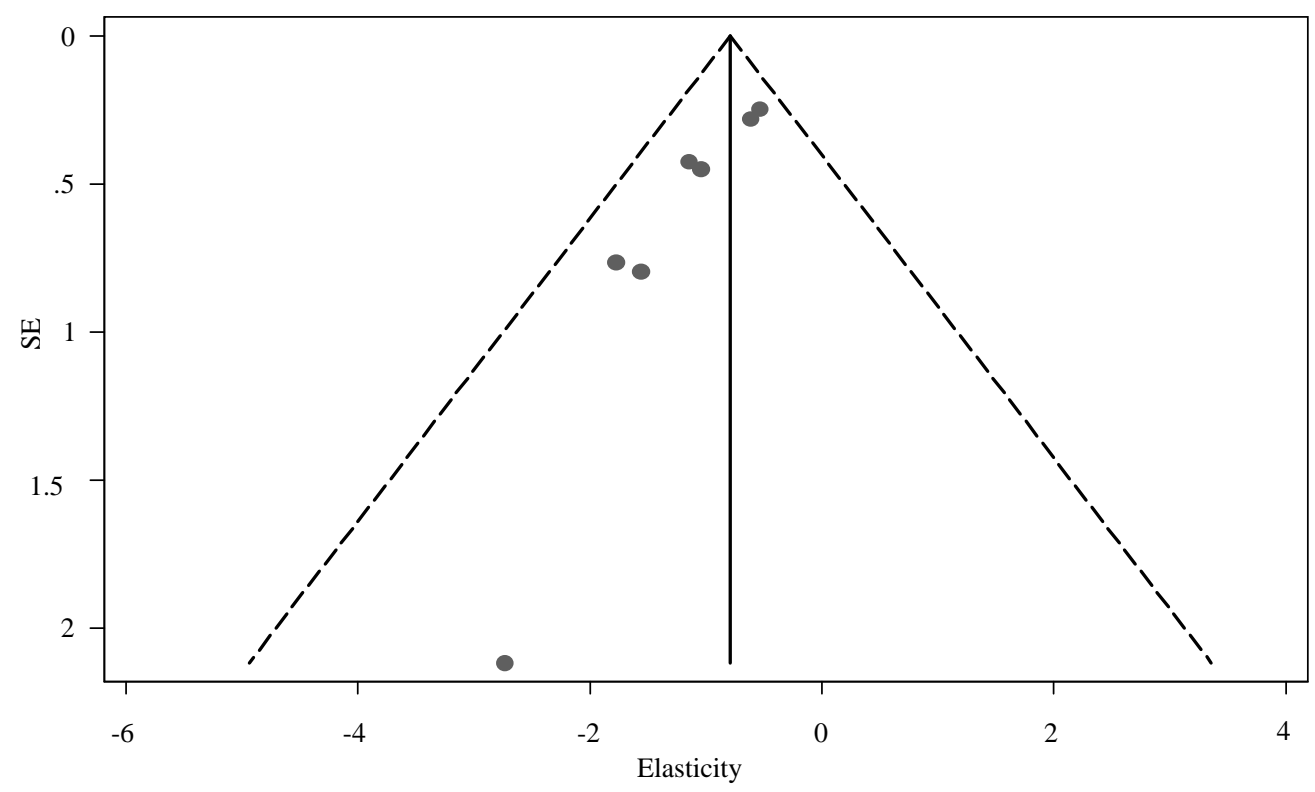

